\title{
Multiple factors in the prediction of risk of recurrent vitreous haemorrhage after sutureless vitrectomy for non-clearing vitreous haemorrhage in patients with diabetic retinopathy
}

Yuhua Ding ${ }^{1+}$, Bangtao $\mathrm{Yao}^{2 \dagger}$, Hui Hang ${ }^{1 *}$ and Hui Ye ${ }^{1 *}$

\begin{abstract}
Background: We aimed to analyse multiple factors in the prediction of risk of postoperative recurrent vitreous haemorrhage (RVH) for non-clearing vitreous haemorrhage in patients with diabetic retinopathy (DR) who underwent sutureless vitrectomy with 23- (23G) or 25-gauge (25G) narrow-gauge systems.
\end{abstract}

Methods: A retrospective consecutive case series design was used. DR patients who underwent sutureless vitrectomy for non-clearing vitreous haemorrhage between June 2017 and October 2019 were enrolled. All operations were performed at a tertiary hospital. Patient demographics and risk factors, including age, gender, duration of diabetes, preoperative fasting blood sugar levels (FBSL), systolic blood pressure (SBP), serum creatinine (Cr), urea, triamcinolone acetonide (TA), electrical coagulation, air-fluid exchange, pan-retinal photocoagulation status (PRP), anti-vascular endothelial growth factor drug (anti-VEGF), and other factors, were recorded. Patients were divided into two groups based on the timing of their postoperative RVH: immediate postoperative RVH (within 2 weeks after operation) and delayed postoperative RVH (beyond 2 weeks after operation).

Results: Overall, 167 eyes (167patients) were enrolled. Seventy eyes were underwent 23G and 25G sutureless vitrectomy performed in 97 eyes, respectively. Postoperative RVH developed in 18 eyes (25.7\%) in Group 23G and in 20 eyes (21.6\%) in Group 25G ( $P=0.540)$. Of these, 3 eyes (4.3\%) had severed RVH in Group 23G compared with 5 eyes (5.2\%) in Group 25G $(P=$ 0.584). Delayed postoperative RVH occurred in 6 eyes (8.6\%) in Group 23G and 8 eyes (8.2\%) in Group 25G (P=0.789). A binomial logistic regression analysis revealed that age, duration of diabetes, and $\mathrm{Cr}$ level were significantly associated with RVH in both Group 23G $(P<0.05)$ and Group 25G $(P<0.05)$.

Conclusions: The incidence and severity of RVH were 25.7 and 4.3\%, respectively, in Group 23G and 21.6 and 5.2\%, respectively, in Group 25G. Thus, the 23G sutureless vitrectomy approach was as safe as the 25G sutureless vitrectomy approach for treating vitreous haemorrhage in patients with DR. A younger age, shorter duration of diabetes, and higher $\mathrm{Cr}$ levels were risk factors for postoperative RVH in sutureless vitrectomy.

Keywords: Recurrent vitreous haemorrhage, Diabetic retinopathy, 23-gauge, 25-gauge, Age, Duration of diabetes, Creatinine

\footnotetext{
* Correspondence: yehui_njmu@163.com; hanghuii@163.com

†Yuhua Ding and Bangtao Yao contributed equally to this work.

'Department of Ophthalmology, Jiangsu Province Hospital, The First

Affiliated Hospital of Nanjing Medical University, Nanjing, Jiangsu Province,

China

Full list of author information is available at the end of the article
}

(c) The Author(s). 2020 Open Access This article is licensed under a Creative Commons Attribution 4.0 International License, which permits use, sharing, adaptation, distribution and reproduction in any medium or format, as long as you give appropriate credit to the original author(s) and the source, provide a link to the Creative Commons licence, and indicate if changes were made. The images or other third party material in this article are included in the article's Creative Commons licence, unless indicated otherwise in a credit line to the material. If material is not included in the article's Creative Commons licence and your intended use is not permitted by statutory regulation or exceeds the permitted use, you will need to obtain permission directly from the copyright holder. To view a copy of this licence, visit http://creativecommons.org/licenses/by/4.0/. The Creative Commons Public Domain Dedication waiver (http://creativecommons.org/publicdomain/zero/1.0/) applies to the data made available in this article, unless otherwise stated in a credit line to the data. 


\section{Background}

Diabetes mellitus (DM) is a common chronic metabolic disease with an increasing prevalence worldwide-more than half a billion individuals are projected to have DM by $2030[1,2]$. Furthermore, diabetic retinopathy (DR) is the most common microvascular complication of DM and is responsible for up to $4.8 \%$ of blindness globally [3]. Despite the use of anti-vascular endothelial growth factor (anti-VEGF) drugs or laser for the treatment of diabetic macular oedema and proliferative DR (PDR) [4-6], vitrectomy surgery remains necessary in up to one-third of eyes with DR [7]. Vitreous haemorrhage $(\mathrm{VH})$ is one of the most common PDR complications and the main cause for sudden vision loss in PDR patients [8]. Non-clearing VH $(\mathrm{NCVH})$ is a good indicator of pars plana vitrectomy (PPV), with vision improvement reported in approximately $75 \%$ of PDR patients after diabetic vitrectomy [9]. However, one of the most common postoperative complications associated with $\mathrm{NCVH}$ is recurrent vitreous haemorrhage (RVH), which may cause visual impairment and require re-operation [10].

The incidence rate of RVH in PDR patients has been reported to range from 11.8 to $75 \%[11,12]$. Early studies have found that the most common causes of $\mathrm{RVH}$ after vitrectomy are fibrovascular ingrowth at the sclerotomy sites, residual or recurrent neovascular membrane formation on the retina, and insufficient retinal photocoagulation $[13,14]$.

In the present study, we focused on a series of patients with DR who were undergoing sutureless $23 \mathrm{G}$ or $25 \mathrm{G}$ vitrectomy for $\mathrm{NCVH}$. We aimed to analyze the incidence and possible risk factors for RVH following sutureless $23 \mathrm{G}$ and $25 \mathrm{G}$ vitrectomies.

\section{Methods}

A retrospective consecutive case series design was used. Patients with DR (both type I diabetes and type II diabetes) undergoing sutureless vitrectomies for NCVH between June 2017 and October 2019 at a tertiary hospital (The First Affiliated Hospital of Nanjing Medical University, Jiangsu Province Hospital) were enrolled. VH cases included cases associated with TRD and fibrovascular membranes, not only simple $\mathrm{VH}$ cases. We excluded cases with a history of previous scleral buckling, PPV, other coexisting ocular disorders such as glaucoma and uveitis, use of sutures for the incisions, silicone oil or inert gas injection during the operation.

A variety of pre-, intra-, and postoperative patient characteristics were assessed. Characteristics included patient age, gender, duration of DM, visual acuity, intraocular pressure (IOP), anterior and posterior segment findings, a history of pan-retinal photocoagulation (PRP), the date of surgery, and any subsequent visits were recorded. Preoperative test results such as fasting blood sugar levels (FBSL), systolic blood pressure (SBP), serum creatinine $(\mathrm{Cr})$, blood urea, prothrombin time $(\mathrm{PT})$, activated partial thromboplastin time (APTT), and prothrombin standardisation ratio (PTINR) were also recorded. Surgical characteristics including usage of triamcinolone acetonide (TA), electrical coagulation, air-fluid exchange, pre-PRP, and anti-VEGF use were determined from the patient's operative record. All patients were followed-up routinely at 1 day, 1 week, 2 weeks, 4 weeks, 2 months, 3 months, and 6 months post-operation. Depending on the commencement of $\mathrm{RVH}$, patients were divided into immediate postoperative RVH (within 2 weeks after operation) and delayed postoperative RVH (beyond 2 weeks after operation) groups. In addition, the severity of postoperative RVH was classified as follows: grade 0 (no haemorrhage), grade 1 (mild-to-moderate: optic disc, macula, and retinal vessel visibility), or grade 2 (severe: retina details were not seen).

All operations were performed by subspecialist vitreoretinal consultants who had more than 10 years of experience. All operations were performed under peribulbar anaesthesia and using the Alcon Constellation 23G or 25G systems (Alcon, Geneva, Switzerland). A wide-angle non-contact indirect viewing system with a built-in image inverter was used in all cases. All patients underwent standard three-port PPV with a combination of dissection and removal of the fibrovascular membranes and vitreoretinal traction. TA staining, electrical coagulation for the remnant of fibrovascular membranes during the operation, air-fluid exchange, and extensive laser photocoagulation surgery were performed as required. No intraocular tamponade (silicone oil or inert gas) was used. At the end of the procedure, cannulas were carefully removed without suturing. Phacoemulsification surgery was performed to remove the clouded lens, which affected the vitrectomy, and an intraocular len was implanted when required. Preoperative anti-VEGF therapy was used in selected patients with informed consent given their extent of neovascularisation. This study followed the tenets of the Declaration of Helsinki. Approval from the appropriate ethics committee was obtained, and informed consent was acquired from all patients before surgery.

\section{Statistical analyses}

All analyses were performed using SPSS version 23.0 for Windows. Descriptive statistics were determined. To compare the two groups, univariate analyses using Chisquared test, Fisher's test and T-test were performed, as appropriate. Binomial logistic regression analyses and multivariate analysis were also performed. A two-sided $p$-value $<0.05$ was considered statistically significant.

\section{Results}

In total, 167 eyes from $167 \mathrm{DM}$ patients with UCVH met the inclusion criteria during the 31-month study 
period. These included 103 male and 64 female patients with a mean age of 52.9 years (range $26-81$ ). From these patients, 70 eyes underwent 23G sutureless PPV and 97 eyes underwent 25G sutureless PPV.

The clinical characteristics and operation-related variables of the participants are shown in Table 1. Clinical characteristics, including gender, age, preoperative SBP, preoperative FBSL, serum Cr, urea and pre-PRP agents, did not differ significantly between Groups 23G and 25G. Duration of DM was shorter in Group 23G than in Group 25G (10 years vs 12 years). In particular, PT, APTT, PT-INR, pre- and postoperative IOP in all patients were in a normal range and as such were excluded from subsequent analyses. The two groups differed in operation-related characteristics such as TA usage, electoral-coagulation usage, air-fluid exchange, and antiVEGF drug usage.

A 6-month follow-up was achieved in all patients from both groups. The incidence and severity of RVH across groups is shown in Table 2. The incidences of postoperative $\mathrm{RVH}$ were 25.7 and $21.6 \%$ in Groups $23 \mathrm{G}$ and $25 \mathrm{G}$, respectively. There were no significant differences between the two groups $(p=0.540)$. There were $3(4.3 \%)$ and $5(5.2 \%)$ severe postoperative $\mathrm{RVH}$ cases (Grade 2) in Groups 23G and 25G, respectively, which ultimately required additional surgeries (e.g., vitreous lavage or PPV). There were no significant differences in postoperative RVH severity between the two groups $(p=0.584)$. Delayed RVH occurred in 6 eyes $((8.6 \%)$ in Group $23 \mathrm{G}$ and in 8 eyes $(8.2 \%)$ in Group 25G $(p=0.789)$ (Table 3).
The analysis of the individuals with or without postoperative RVH is shown in Table 4. Patient age $(p=0.006$, $p<0.001)$, duration of $\mathrm{DM}(p=0.007, p=0.003)$, and serum $\mathrm{Cr}(p=0.002, p=0.009)$ were significantly different between participants with and without postoperative RVH in both Groups 23G and 25G. Additionally, the level of urea $(p=0.005)$ was significantly different between participants with and without postoperative RVH in Group 25G. A binomial logistic regression analysis revealed risk factors of postoperative RVH (Table 5). Age ( $p=0.019, p=0.004)$, duration of DM ( $p=0.046, p=0.02)$, and serum Cr levels $(p=0.006, p=0.042)$ were significantly different between participants with and without postoperative RVH in both Groups 23G and 25G.

\section{Discussion}

With the rapid development of surgical techniques and instruments, the incidence of postoperative RVH in PDR has fallen significantly from $75 \%$ in the 1980 s to approximately $11.8-40 \%[11,12,15,16]$. Khuthaila et al. reported an incidence rate of $32 \%$ for postoperative $\mathrm{RVH}$ with 23G PPV in PDR patients [17], while Mahallngam et al. reported an RVH incidence of $21.6 \%$ [18]. Similarly, in the present study, the incidences of postoperative RVH were 25.7 and $21.6 \%$ in Groups $23 \mathrm{G}$ and 25G, respectively.

Research is ongoing to elucidate the risk factors of postoperative RVH. Mahallngam et al. and Tolentino et al. reported that a younger patient age was significantly associated with postoperative RVH $[18,19]$. In the present study also, the age influenced postoperative

Table 1 Clinical characteristics and operation-related variables of the study participants

\begin{tabular}{|c|c|c|c|}
\hline Characteristics & $23 G$ & $25 G$ & p-value \\
\hline Eyes, $n$ & 70 & 97 & \\
\hline Male, n(\%) & $43(61.4)$ & $60(61.9)$ & 0.955 \\
\hline Age, years (mean $\pm S D$ ) & $54.70 \pm 11.31$ & $51.63 \pm 12.74$ & 0.109 \\
\hline Preoperative systolic blood pressure, $\mathrm{mmHg}($ mean \pm SD) & $138.01 \pm 18.42$ & $136.13 \pm 20.17$ & 0.539 \\
\hline \multicolumn{4}{|l|}{ Diabetes } \\
\hline Duration, years & $10.00(5.00-15.00)$ & $12.00(6.50-16.50)$ & 0.041 \\
\hline Preoperative fasting blood glucose level, mmol/L & $5.62(4.70-7.41)$ & $5.96(5.05-7.19)$ & 0.639 \\
\hline Serum creatinine, $\mu \mathrm{mol} / \mathrm{L}$ & $77.55(58.78-104.93)$ & $76.00(59.15-127.00)$ & 0.359 \\
\hline Urea, mmol/L & $6.51(5.41-8.88)$ & $6.67(4.81-8.90)$ & 0.502 \\
\hline Triamcinolone acetonide usage, n(\%) & $63(90.0)$ & $59(60.8)$ & $<0.001$ \\
\hline Elctral-coagulation usage, n(\%) & $12(17.1)$ & $7(7.2)$ & 0.046 \\
\hline Air-fluid exchange, n(\%) & $66(94.3)$ & $66(68.0)$ & $<0.001$ \\
\hline Pre-pan-retinal photocoagulation, n(\%) & $12(17.1)$ & $15(15.5)$ & 0.771 \\
\hline Anti-vascular endothelial growth drug usage, n(\%) & $10(14.3)$ & $33(34.0)$ & 0.004 \\
\hline \multicolumn{4}{|l|}{ Intraocular pressure, $\mathrm{mmHg}$} \\
\hline preoperative IOP & $16.45(15.38-17.53)$ & $16.40(14.25-17.40)$ & 0.092 \\
\hline postoperative IOP & $16.00(14.93-16.78)$ & $15.31(14.25-16.40)$ & 0.078 \\
\hline
\end{tabular}


Table $\mathbf{2}$ Incidence rate and severity of RVH

\begin{tabular}{|c|c|c|c|}
\hline & $23 G$ & $25 G$ & $p$-value \\
\hline \multicolumn{4}{|l|}{ Incidence rate } \\
\hline $\mathrm{RVH}, \mathrm{n}(\%)$ & $18(25.7)$ & 21 (21.6) & 0.540 \\
\hline No RVH, n(\%) & $52(74.3)$ & 76 (78.4) & \\
\hline \multicolumn{4}{|l|}{ Grade } \\
\hline Grade 0, n(\%) & $52(74.3)$ & 76 (78.35) & 0.584 \\
\hline Grade 1, n(\%) & $15(21.4)$ & $16(16.5)$ & \\
\hline Grade 2, n(\%) & $3(4.3)$ & $5(5.15)$ & \\
\hline
\end{tabular}

RVH. There are two possible explanations for this; one related to surgery and the other with patients themselves. First, it is more difficult to induce a complete posterior vitreous detachment in younger patients than the older ones because of their stronger vitreoretinal adhesions. When a residual split posterior vitreous cortex remains firmly attached to the retina, it serves as a natural scaffold for the proliferation of neovascularisation membrane. Vitreous contraction and subsequent traction on unhealthy fibrovascular membranes can induce postoperative re-bleeding. A second explanation for the impact of patient age on postoperative $\mathrm{RVH}$ is that the onset of PDR in younger patients indicates a more rapid disease progression and thus, more aggressive disease. In some cases, this also indicates a broader area of active neovascularisation. Given this, the increasing numbers of unhealthy neovascular vessels bleed easily.

The present study also identified the duration of DM as a predictor of increased postoperative RVH risk. Epidemiologic data reveals that PDR almost never develops within the first 10 years of DM onset [20]. But in our study, the patients happened postoperative $\mathrm{RVH}$ experienced less than 10 years duration (5 years, 23G VS 6 years, 25G). The estimated prevalence of diabetes in China is $12 \%$, or over 100 million patients $[21,22]$. The burden of diabetes has consistently risen in China over the past two decades and is predicted to continue to rise [21,22] and most of these cases are undiagnosed [21, 22]. Combined with the current situation of diabetes in China, a possible explanation for this is that some patients lack an awareness of their DM and their disease may develop for many years without any diagnosis or treatment. The shorter duration provided by the patient is not the real duration of DM. We hypothesized that a shorter duration of DM at the

Table 3 Immediate RVH and delayed RVH

\begin{tabular}{llll}
\hline & $23 G$ & $25 G$ & p-value \\
\hline immediate RVH, n & 12 & 13 & 0.789 \\
delayed RVH, n & 6 & 8 & \\
no RVH, n & 52 & 76 & \\
\hline
\end{tabular}

time of presentation may reflect the patient's ignorance of the disease, leaving it uncontrolled for many years. In patients with a longer duration of DM, treatment might have been used more consistently and for a longer period; therefore, their degree of PDR may be less severe. More studies should be made to further study the relationship between the shorter duration of DM at the time of presentation and the postoperative RVH. Therefore, we contend that the clinicians should pay more attention to the patients with a shorter DM onset time (and thus later detection).

In the present study, we reported for the first time that $\mathrm{Cr}$ was a novel RVH risk predictor and strongly associated with postoperative $\mathrm{RVH}$. $\mathrm{Cr}$ is the most common index used for renal function. Compensatory kidney function is very powerful. The $\mathrm{Cr}$ values won't be increased, unless the degree of kidney damage accounts for more than half of the kidney. Higher $\mathrm{Cr}$ values in the present study represented poor renal function and a poor general state of health due to poor control of preoperation blood sugar levels. Kussman et al. reported that in the typical clinical course of diabetic nephropathy, the mean duration of DM at the onset of early renal function failure was approximately 19 years [23]. So the higher the $\mathrm{Cr}$ value reflects the longer duration of $\mathrm{DM}$ in reality. Combined with the risk predictor of postoperative RVH mentioned above, a shorter duration of DM at the time of presentation, which confirms again that the disease had been ignored and uncontrolled for many years. Given this, the patients with higher $\mathrm{Cr}$ values in the present study may have had more aggressive PDR, thus increasing their risk of postoperative RVH.

As has previously been found, silicone oil and inert gases such as SF6 and C3F8 may decrease the incidence of postoperative $\mathrm{RVH}$, especially in early $\mathrm{RVH}$ cases [24]. One possible reason for this may be that longstanding mechanical tamponade of fragile retinal vessels by oil or gas bubbles that occurs with this procedure. This tamponade also concentrates coagulation factors within the close proximity of bleeding sites, thereby promoting the re-establishment of vascular integrity. We, therefore, excluded cases from the present study in which silicone oil or inert gas tamponade appeared to minimise any interference by these factors and to isolate other predictors of postoperative $\mathrm{RVH}$ risk.

After the first commercially available narrow-gauge vitrectomy system was described by Fujii et al. in 2002, a high number of narrow-gauge systems were employed worldwide [25]. These revolutionary advances led to faster postoperative recovery, less postoperative discomfort, reduced surgically-induced astigmatisms, and a quicker entry and exit from the eye [26]. Furthermore, 23G devices retained the fluid dynamics and instrumental rigidity offered by $20 \mathrm{G}$ systems and required minimal 
Table 4 Characteristics of individuals with or without postoperative RVH

\begin{tabular}{|c|c|c|c|c|c|c|}
\hline & \multicolumn{3}{|l|}{$23 \mathrm{G}(n=70)$} & \multicolumn{3}{|l|}{$25 \mathrm{G}(n=97)$} \\
\hline & No RVH $(n=52)$ & $\mathrm{RVH}(n=18)$ & $\begin{array}{l}\mathrm{p}- \\
\text { value }\end{array}$ & No $\mathrm{RVH}(n=76)$ & $\operatorname{RVH}(n=21)$ & $\begin{array}{l}p^{-} \\
\text {value }\end{array}$ \\
\hline Sex (male/female) & $31(59.6)$ & $12(66.7)$ & 0.596 & $46(60.5)$ & $14(66.7)$ & 0.608 \\
\hline Age, years (mean $\pm S D$ ) & $56.94 \pm 10.45$ & $48.22 \pm 11.46$ & 0.006 & $53.96 \pm 11.85$ & $43.19 \pm 12.52$ & $\begin{array}{l}< \\
0.001\end{array}$ \\
\hline Duration of diabetes, years & $\begin{array}{l}10.00(5.00- \\
17.00)\end{array}$ & $5.00(3.00-9.25)$ & 0.007 & $12.50(8.50-17.00)$ & $6.00(2.00-15.00)$ & 0.003 \\
\hline Preoperative fasting blood glucose level, mmol/L & $5.88(4.88-7.44)$ & $5.27(3.99-6.97)$ & 0.149 & $5.93(5.09-7.06)$ & $6.04(4.21-7.97)$ & 0.646 \\
\hline Preoperative systolic blood pressure, $\mathrm{mmHg}$ & $137.60(100-183)$ & $139.22(92-187)$ & 0.702 & $135.03(88-190)$ & $140.14(100-187)$ & 0.464 \\
\hline Serum creatinine, $\mu \mathrm{mol} / \mathrm{L}$ & $\begin{array}{l}70.40(53.33- \\
88.78)\end{array}$ & $\begin{array}{l}108.80(66.78- \\
231.28)\end{array}$ & 0.002 & $\begin{array}{l}71.80(56.08- \\
118.00)\end{array}$ & $\begin{array}{l}95.00(68.80- \\
373.60)\end{array}$ & 0.009 \\
\hline Urea, mmol/L & $6.47(5.17-7.58)$ & $8.14(5.42-13.36)$ & 0.066 & $5.88(4.79-7.81)$ & $9.40(5.49-14.04)$ & 0.005 \\
\hline Triamcinolone acetonide usage, $\mathrm{n}(\%)$ & $48(92.3)$ & $15(83.3)$ & 0.523 & $45(59.2)$ & $14(66.7)$ & 0.536 \\
\hline $\begin{array}{l}\text { Electral-coagulation usage (fibrovascular membrane), } \\
n(\%)\end{array}$ & $10(19.2)$ & $2(11.1)$ & 0.671 & $6(7.9)$ & $1(4.8)$ & 0.988 \\
\hline Air-fluid exchange, n(\%) & $49(94.2)$ & $17(94.4)$ & 1 & $52(68.4)$ & $14(66.7)$ & 0.879 \\
\hline Pre-pan-retinal photocoagulation, n(\%) & $9(17.3)$ & $3(16.7)$ & 1 & $14(18.4)$ & $1(4.8)$ & 0.233 \\
\hline Anti-vascular endothelial growth drug usage, $\mathrm{n}(\%)$ & $9(17.3)$ & 1 (5.6) & 0.402 & $25(32.9)$ & $8(38.1)$ & 0.656 \\
\hline
\end{tabular}

Table 5 Results of binomial logistic regression analysis for risk factors of postoperative RVH

\begin{tabular}{|c|c|c|c|c|c|c|c|c|}
\hline & \multicolumn{4}{|l|}{$23 \mathrm{G}$} & \multicolumn{4}{|l|}{$25 \mathrm{G}$} \\
\hline & \multicolumn{2}{|l|}{ Univariate } & \multicolumn{2}{|l|}{ Multivariate } & \multicolumn{2}{|l|}{ Univariate } & \multicolumn{2}{|l|}{ Multivariate } \\
\hline & $\mathrm{OR}(95 \% \mathrm{Cl})$ & $\begin{array}{l}p- \\
\text { value }\end{array}$ & $\mathrm{OR}(95 \% \mathrm{Cl})$ & $\begin{array}{l}p- \\
\text { value }\end{array}$ & $\mathrm{OR}(95 \% \mathrm{Cl})$ & $\begin{array}{l}p^{-} \\
\text {value }\end{array}$ & $\mathrm{OR}(95 \% \mathrm{Cl})$ & $\begin{array}{l}\mathrm{p}- \\
\text { value }\end{array}$ \\
\hline Sex (male/female) & $\begin{array}{l}1.355(0.440- \\
4.176)\end{array}$ & 0.597 & $\begin{array}{l}4.226(0.476- \\
37.514)\end{array}$ & 0.196 & $\begin{array}{l}0.767(0.277- \\
2.120)\end{array}$ & 0.609 & $\begin{array}{l}2.509(0.348- \\
18.093)\end{array}$ & 0.361 \\
\hline Age, years & $\begin{array}{l}0.927(0.877- \\
0.980)\end{array}$ & 0.008 & $\begin{array}{l}0.894(0.814- \\
0.982)\end{array}$ & 0.019 & $\begin{array}{l}0.925(0.881- \\
0.970)\end{array}$ & 0.001 & $\begin{array}{l}0.888(0.819- \\
0.963)\end{array}$ & 0.004 \\
\hline Duration of diabetes, years & $\begin{array}{l}0.872(0.784- \\
0.971)\end{array}$ & 0.012 & $\begin{array}{l}0.833(0.697- \\
0.997)\end{array}$ & 0.046 & $\begin{array}{l}0.888(0.814- \\
0.968)\end{array}$ & 0.007 & $\begin{array}{l}0.835(0.716- \\
0.972)\end{array}$ & 0.02 \\
\hline Preoperative fasting blood glucose level & $\begin{array}{l}0.784(0.586- \\
1.048)\end{array}$ & 0.101 & $\begin{array}{l}0.928(0.628- \\
1.371)\end{array}$ & 0.708 & $\begin{array}{l}1.068(0.887- \\
1.287)\end{array}$ & 0.488 & $\begin{array}{l}1.182(0.851- \\
1.640)\end{array}$ & 0.319 \\
\hline Preoperative systolic blood pressure & $\begin{array}{l}1.005(0.976- \\
1.035)\end{array}$ & 0.745 & $\begin{array}{l}1.019(0.969- \\
1.072)\end{array}$ & 0.467 & $\begin{array}{l}1.013(0.989- \\
1.037)\end{array}$ & 0.304 & $\begin{array}{l}0.993(0.948- \\
1.041)\end{array}$ & 0.783 \\
\hline Serum creatinine, $\mu \mathrm{mol} / \mathrm{L}$ & $\begin{array}{l}1.013(1.002- \\
1.024)\end{array}$ & 0.02 & $\begin{array}{l}1.028(1.008- \\
1.049)\end{array}$ & 0.006 & $\begin{array}{l}1.006(1.002- \\
1.010)\end{array}$ & 0.004 & $\begin{array}{l}1.009(1.000- \\
1.019)\end{array}$ & 0.042 \\
\hline Blood urea & $\begin{array}{l}0.995(0.972- \\
1.019)\end{array}$ & 0.703 & $\begin{array}{l}0.986(0.929- \\
1.046)\end{array}$ & 0.637 & $\begin{array}{l}1.285(1.107- \\
1.491)\end{array}$ & 0.001 & $\begin{array}{l}1.226(0.968- \\
1.553)\end{array}$ & 0.09 \\
\hline Triamcinolone acetonide usage & $\begin{array}{l}0.417(0.084- \\
2.075)\end{array}$ & 0.285 & $\begin{array}{l}0.626(0.057- \\
6.861)\end{array}$ & 0.701 & $\begin{array}{l}1.378(0.499- \\
3.806)\end{array}$ & 0.536 & $\begin{array}{l}3.777(0.512- \\
27.84)\end{array}$ & 0.192 \\
\hline $\begin{array}{l}\text { Electral-coagulation usage (fibrovascular } \\
\text { membrane) }\end{array}$ & $\begin{array}{l}0.525(0.104- \\
2.663)\end{array}$ & 0.437 & $\begin{array}{l}1.103(0.057- \\
21.471)\end{array}$ & 0.948 & $\begin{array}{l}0.583(0.066- \\
5.132)\end{array}$ & 0.627 & $\begin{array}{l}0.187(0.006- \\
6.260)\end{array}$ & 0.349 \\
\hline Air-fluid exchange & $\begin{array}{l}1.041(.101- \\
10.692)\end{array}$ & 0.973 & $\begin{array}{l}0.156(0.005- \\
5.348)\end{array}$ & 0.303 & $\begin{array}{l}0.923(0.330- \\
2.581)\end{array}$ & 0.879 & $\begin{array}{l}0.858(0.124- \\
5.934)\end{array}$ & 0.876 \\
\hline Pre-pan-retinal photocoagulation & $\begin{array}{l}0.956(0.228- \\
4.004)\end{array}$ & 0.95 & $\begin{array}{l}2.350(0.221- \\
25.009)\end{array}$ & 0.479 & $\begin{array}{l}0.221(0.027- \\
1.791)\end{array}$ & 0.157 & $\begin{array}{l}0.109(0.008- \\
1.528)\end{array}$ & 0.1 \\
\hline $\begin{array}{l}\text { Anti-vascular endothelial growth drug } \\
\text { usage }\end{array}$ & $\begin{array}{l}0.281(0.033- \\
2.391)\end{array}$ & 0.245 & $\begin{array}{l}0.083(0.003- \\
2.690)\end{array}$ & 0.161 & $\begin{array}{l}1.255(0.461- \\
3.420)\end{array}$ & 0.657 & $\begin{array}{l}0.456(0.074- \\
2.795)\end{array}$ & 0.396 \\
\hline
\end{tabular}


changes in the surgical technique. The $25 \mathrm{G}$ system further improved fluidics and rigidity. Owing to these advantages, both two narrow-gauge systems are often used by the surgeons. Thus, in the present study, patients with DR who underwent both sutureless 23G and 25G PPV for NCVH were included. While the incisions created during 25G PPV do not require sutures, 23G PPV incisions sometimes do. As such, we only included the patients who underwent sutureless 23G PPV in the present study to eliminate any influence associated with the sutures.

One of the disadvantages of the sutureless technique is hypotony. It remains unclear whether hypotony is significantly correlated with postoperative RVH; however, both the advantages and disadvantages have been reported previously in the literature [12, 27]. In the present study, both pre- and postoperative IOP were within the normal range. Thus, any relationship between the hypotony and postoperative RVH was not assessed in this study.

The present study has a few limitations. One was the number of patients who used anti-VEGF drugs. AntiVEGF drug injection before vitrectomy causes regression of active neovascularization, at least in the short term [28]. It reduces the likelihood of intraoperative hemorrhage in diabetic vitrectomy, makes the surgery quicker and easier [29]. However, in the previous literature, it still remains unclear whether anti-VEGF is significantly correlated with postoperative RVH [30]. Due to the high cost of anti-VEGF drugs, few people can afford this treatment and thus, a few patients included in this study used them. Therefore, in the present study, the relationship between anti-VEGF drug use and postoperative RVH remains unclear. A larger sample size is needed to explore this aspect more closely. Another limitation was that there were few cases of delayed or severe postoperative RVH among the participants of the present study. Hence, we were unable to investigate the risk factors associated with delayed and severe postoperative RVH. Third, only preoperative FBSL were recorded. A high level of preoperative FBS only reflected the difficulty of glycemic control during a short period, and can be influenced by many facts including perioperative stress. Further studies are required to clarify the relationship between perioperative hyperglycemia and postoperative complications. Fourth, due to the small number of patients who implemented PRP before operation, the relationship between preoperative PRP and postoperative RVH could not be observed in our study. Because of the huge number of Chinese diabetes patients, few patients can follow the doctor's instructions to regularly check the blood glucose level and eye conditions, a lot of patients fail to implement PRP in time, but directly have $\mathrm{VH}$, and have to do surgical intervention.
Fifth, number of patients with neovascularization membrane is small, no positive results can be observed in our study, but this does not prove that there is no correlation between neovascularization membrane and postoperative $\mathrm{RVH}$. In the future study, we are going to collect more patients for further in-depth and sub analysis.

\section{Conclusions}

The incidence and severity of RVH were 25.7 and $4.3 \%$, respectively, in Group 23G and 21.6 and 5.2\%, respectively, in Group 25G. The findings of our study suggest that 23G sutureless vitrectomy was as safe as 25G sutureless vitrectomy for $\mathrm{NCVH}$ in patients with DR. The practical applications of the study to clinical domains and public policy deserved attention. A younger age, shorter duration of DM, and higher Cr levels were significant predictors of postoperative $\mathrm{RVH}$ risk in patients who underwent sutureless vitrectomy.

\section{Abbreviations \\ 23G or 25G: 23- or 25-gauge narrow-gauge; APT: Activated partial thromboplastin time; Cr: Creatinine; DM: Diabetes mellitus; DR: Diabetic retinopathy; FBSL: Fasting blood sugar level; IOP: Intraocular pressure; NCVH: Non-clearing vitreous haemorrhage; PDR: Proliferative diabetic retinopathy; PPV: Pars plana vitrectomy; PRP: Pan-retinal photocoagulation; PT: Prothrombin time; PT-INR: Prothrombin standardisation ratio; RVH: Recurrent vitreous haemorrhage; SBP: Systolic blood pressure; TA: Triamcinolone acetonide; VEGF: Vascular endothelial growth factor; $\mathrm{VH}$ : Vitreous haemorrhage}

\section{Acknowledgements}

Not applicable.

\section{Authors' contributions}

YHD collected the data of the patient, consulted literatures and wrote the manuscript; BTY edited the manuscript, analyzed the data and dealt with the tables; $\mathrm{HH}$ gave useful suggestions on writing and improved the manuscript; HY contributed design of study and approved the submitted version. YHD and BTY contributed equally to this article, they are co-first authors of the article. All authors read and approved the final manuscript.

\section{Funding}

The current study was supported by Jiangsu University Clinical Medical Science and Technology Development Fund (Natural Science) Project 2018 (grant nos. JLY20180034). The funder (Bangtao Yao) is the co-first author of the article, he edited the manuscript, analyzed the data and dealt with the tables. The funding had no role in study design, data collection and publication fee.

Availability of data and materials

The datasets used and analyzed during the current study are available from the corresponding author on reasonable request.

Ethics approval and consent to participate Approval was obtained from the ethics committee of Jiangsu Province Hospital, and informed written consent had been obtained from the patients.

Consent for publication

Not applicable.

Competing interests

The authors declare that they have no competing interests. 


\section{Author details}

'Department of Ophthalmology, Jiangsu Province Hospital, The First Affiliated Hospital of Nanjing Medical University, Nanjing, Jiangsu Province, China. ${ }^{2}$ Department of Ophthalmology, Lishui District People's Hospital, Lishui branch of Southeast University Affiliated Zhongda Hospital, Nanjing, Jiangsu Province, China.

Received: 8 April 2020 Accepted: 26 June 2020

Published online: 16 July 2020

\section{References}

1. Rathmann W, Giani G. Global prevalence of diabetes: estimates for the year 2000 and projections for 2030. Diabetes Care. 2004;27(10):2568-9.

2. Whiting DR, Guariguata L, Weil C, Shaw J. IDF diabetes atlas: global estimates of the prevalence of diabetes for 2011 and 2030. Diabetes Res Clin Pract. 2011;94(3):311-21.

3. Fong DS, Aiello L, Gardner TW, King GL, Blankenship G, Cavallerano JD, et al. Retinopathy in diabetes. Diabetes Care. 2004;27(suppl 1):s84-7.

4. Elman MJ, Ayala A, Bressler NM, Browning D, Flaxel CJ, Glassman AR, et al. Intravitreal ranibizumab for diabetic macular edema with prompt versus deferred laser treatment: 5-year randomized trial results. Ophthalmology. 2015;122(2):375-81.

5. Nguyen QD, Brown DM, Marcus DM, Boyer DS, Patel S, Feiner L, et al. Ranibizumab for diabetic macular edema: results from 2 phase III randomized trials: RISE and RIDE. Ophthalmology. 2012;119(4):789-801.

6. Gross JG, Glassman AR, Jampol LM, Inusah S, Aiello LP, Antoszyk AN, et al. Panretinal photocoagulation vs intravitreous ranibizumab for proliferative diabetic retinopathy: a randomized clinical trial. JAMA. 2015;314(20):2137-46.

7. Bhavsar AR, Torres K, Glassman AR, Jampol LM, Kinyoun JL. Evaluation of results 1 year following short-term use of ranibizumab for vitreous hemorrhage due to proliferative diabetic retinopathy. JAMA Ophthalmol. 2014;132(7):889-90.

8. Shi L, Yi-Fei H. Postvitrectomy diabetic vitreous hemorrhage in proliferative diabetic retinopathy. J Res Med Sci. 2012;17:865-71.

9. Yorston D, Wickham L, Benson S, Bunce C, Sheard R, Charteris D. Predictive clinical features and outcomes of vitrectomy for proliferative diabetic retinopathy. Br J Ophthalmol. 2008;92:365-8

10. Yang CM. Surgical treatment for diabetic retinopathy: 5-year experience. J Formos Med Assoc. 1998;97:477-84.

11. Schachat AP, Oyakawa RT, Michels RG, Rice TA. Complications of vitreous surgery for diabetic retinopathy: II. Postoperative complications Ophthalmology. 1983;90(5):522-30.

12. Lee BJ, Yu HG. Vitreous hemorrhage after the 25-gauge transconjunctival sutureless vitrectomy for proliferative diabetic retinopathy. Retina. 2010; 30(10):1671-7.

13. Yan H, Cui J, Lu Y, Yu J, Chen S, Xu Y. Reasons for and management of postvitrectomy vitreous hemorrhage in proliferative diabetic retinopathy Curr Eye Res. 2010;35:308-13.

14. Zaninetti M, Petropoulos IK, Pournaras CJ. Proliferative diabetic retinopathy: Vitreo-retinal complications are often related to insufficient retinal photocoagulation. J Fr Ophtalmol. 2005;28:381-4.

15. Fujii GY, De Juan E Jr, Humayun MS, Chang TS, Pieramici DJ, Barnes A, et al. Initial experience using the transconjunctival sutureless vitrectomy system for vitreoretinal surgery. Ophthalmology. 2002:109:1814-20.

16. Sima $\mathrm{P}$, Zoran $\mathrm{T}$. Long-term results of vitreous surgery for proliferative diabetic retinopathy. Doc Ophthalmol. 1994:87:223-32.

17. Yeh PT, Yang CM, Yang CH, Huang JS. Cryotherapy of the anterior retina and sclerotomy sites in diabetic vitrectomy to prevent recurrent vitreous hemorrhage: an ultrasound biomicroscopy study. Ophthalmology. 2005;112: 2095-102.

18. Khuthaila MK, Hsu J, Chiang A, DeCroos FC, Milder EA, Setlur V, et al. Postoperative vitreous hemorrhage after diabetic 23-gauge pars plana vitrectomy. Am J Ophthalmol. 2013;155:757-63 763.e1-2.

19. Tolentino FI, Cajita VN, Gancayco T, Skates S. Vitreous hemorrhage after closed vitrectomy for proliferative diabetic retinopathy. Ophthalmology. 1989;96:1495-500

20. Klein R, Klein BE, Moss SE, Davis MD, DeMets DL. The Wisconsin epidemiologic study of diabetic retiopathy. II. Prevalence and risk of diabetic retinopathy when age at diagnosis is less than 30 years. Arch Ophthalmol. 1984;102:520-6.
21. Xu Y, Wang L, He J, Bi Y, Li M, Wang T, et al. Prevalence and control of diabetes in Chinese adults. Jama. 2013;310(9):948-59.

22. Yang W, Lu J, Weng J, Jia W, Ji L, Xiao J, et al. Prevalence of diabetes among men and women in China. N Engl J Med. 2010;362(12):1090-101.

23. Kussman MJ, Goldstein H, Gleason RE. The clinical course of diabetic nephropathy. JAMA. 1976;236(16):1861-3.

24. Mahalingam P, Topiwalla T, Ganesan G. Vitreous rebleed following sutureless vitrectomy: incidence and risk factors. Indian J Ophthalmol. 2018; 66:558-61.

25. Yang $\mathrm{CM}$, Yeh PT, Yang $\mathrm{CH}$. Intravitreal long-acting gas in the prevention of early postoperative vitreous hemorrhage in diabetic vitrectomy. Ophthalmology. 2007;114(4):710-5

26. Nagpal M, Wartikar S, Nagpal K. Comparison of clinical outcomes and wound dynamics of sclerotomy ports of 20,25, and 23 gauge vitrectomy. Retina. 2009:29:225-31.

27. Altan T, Acar N, Kapran Z, Unver YB, Ozdogan S. Transconjunctival 25-gauge sutureless vitrectomy and silicone oil injection in diabetic tractional retinal detachment. Retina. 2008;28:1201-6.

28. Yang CM, Yeh PT, Yang CH, Chen MS. Bevacizumab pretreatment and longacting gas infusion on vitreous clear-up after diabetic vitrectomy. Am J Ophthalmol. 2008;146(2):211-7.

29. Rizzo S, Genovesi-Ebert F, Di Bartolo E, Vento A, Miniaci S, Williams G. Injection of intravitreal bevacizumab (Avastin) as a preoperative adjunct before vitrectomy surgery in the treatment of severe proliferative diabetic retinopathy (PDR). Graefes Arch Clin Exp Ophthalmol. 2008;246(6):837-42.

30. Berk Ergun S, Toklu Y, Cakmak HB, Raza S, Simsek S. The effect of intravitreal bevacizumab as a pretreatment of vitrectomy for diabetic vitreous hemorrhage on recurrent hemorrhage. Semin Ophthalmol. 2015;30(3):177-80.

\section{Publisher's Note}

Springer Nature remains neutral with regard to jurisdictional claims in published maps and institutional affiliations.

Ready to submit your research? Choose BMC and benefit from:

- fast, convenient online submission

- thorough peer review by experienced researchers in your field

- rapid publication on acceptance

- support for research data, including large and complex data types

- gold Open Access which fosters wider collaboration and increased citations

- maximum visibility for your research: over $100 \mathrm{M}$ website views per year

At $\mathrm{BMC}$, research is always in progress.

Learn more biomedcentral.com/submission 